\title{
Gender and managerial competence: a comparison of male and female first-line nurse managers in Indonesia
}

Original article

\author{
Joko Gunawan ${ }^{a}$, Yupin Aungsurocha,*, Mary L. Fisher ${ }^{\mathrm{b}, \mathrm{c}}$, Anna M. McDaniel ${ }^{\mathrm{b}}$ \\ aFaculty of Nursing, Chulalongkorn University Bangkok, Bangkok 10330, Thailand \\ ${ }^{b}$ College of Nursing, University of Florida, Gainesville, Florida 32610, USA \\ 'School of Nursing, Indiana University, Indianapolis, Indiana 46202, USA
}

Received: 27 April 2020; Accepted: 26 June 2020; Published: 20 March 2021

\begin{abstract}
Objective: First-line nurse managers are more likely to work according to gender beliefs and stereotypes, which may affect their managerial competence. This study is aimed at comparing managerial competence of male and female first-line nurse managers in public hospitals in Indonesia.

Methods: This study employed a descriptive comparative approach with a cross-sectional survey with a total of 256 participants selected from 18 public hospitals. To measure managerial competence, the managerial competence scale for Indonesian first-line nurse managers was used. Data were analyzed using descriptive analyses using mean, standard deviation, and Independent $t$-test. Results: Managerial competence of male and female first-line nurse managers was not significantly different $(P=0.555)$. Female nurse managers descriptively reported/received higher ranking in facilitating spiritual nursing care, managing self, staffing and professional development, utilizing informatics, and applying quality care improvement. Male nurse managers reported higher in leadership and financial management.

Conclusions: Female and male first-line nurse managers should be treated equally for leadership and managerial development.
\end{abstract}

Keywords: nurse administrators $\bullet$ male $\bullet$ female $\bullet$ managerial competence $\bullet$ Indonesia

(c) Shanxi Medical Periodical Press.

\section{Introduction}

The complex and unpredictable health-care system today requires the competent first-line nurse managers to ensure that everyday nursing practice brings high outcomes for patients and nurses, and to guarantee that the vision and mission of the hospital are achieved effectively. ${ }^{1}$ Leadership and managerial competence of first-line nurse managers are the key to success of each hospital, ${ }^{2}$ which is the reason for the assessment regarding their competence warrants consideration.

Our study focuses on gender analysis in the comparison of managerial competence of male and female first-line nurse managers. Studies revealed that male and female managers work and behave differently in accordance with gender beliefs and stereotypes. ${ }^{3,4}$

How to cite this article: Gunawan J, Aungsuroch Y, Fisher ML, McDaniel AM. Gender and managerial competence: a comparison of male and female first-line nurse managers in Indonesia. Front Nurs. 2021;1:49-58.

\footnotetext{
* Corresponding author.

E-mail: yaungsuroch@gmail.com (Y. Aungsuroch).
} 
Male managers are characterized with directive and command-and-control behavior, whereas female managers are most likely related to collaborative, participative, and transformative behavior. ${ }^{5}$ These stereotypes are basically derived from the communal qualities in women, such as being sympathetic, friendly, caring, helping, and supporting; and for men, these are derived from masculine qualities, such as being dominant, ambitious, control, and confident. ${ }^{6}$

Additionally, the gender comparison is also influenced by three paradigms, namely (1) gender-blind view assuming that male and female leaders are similar and therefore should have the same treatment, (2) gender-conscious view, where it is believed that male and female leaders are different and therefore should be treated accordingly, and (3) perception creates reality, which assumes that although male and female leaders are the same, people still think they are different, which stereotypically creates barriers among them. ${ }^{7}$

In spite of those perspectives, it also needs to be considered that although the number of men continues to increase in the nursing workforce today, nursing is still stereotypically considered a women-dominated profession in the world. ${ }^{8}$ The proportion of Indonesian nurses today consists of $70 \%$ of females $(256,326)$ and $30 \%$ of males $(103,013) .{ }^{9}$ As a consequence, a negative gender stereotype among male nurses in the community still persists, which is likely related to questions that the male nurses can lift the heavier patients to complete a job and concerns about being gay. ${ }^{10,11}$ Literature also shows that if men working in the jobs that are mostly associated with male and male stereotypes, they will show the attribute of men with their masculinity; otherwise, if men work in the women-dominated jobs, they will show less masculinity image, which is perhaps influenced by feminism. ${ }^{12}$ Thus, this issue may influence the competence and performance of male nurses in their works.

However, as there are lack of studies exploring this issue in nursing, especially, in Indonesia, it is too weak to draw a conclusion if there is an influence of gender on managerial competence of first-line nurse managers. However, the emphasis on gender analysis in this study is not to create inequities among male and female nurse managers in working place but to address the strengths and weaknesses among them to identify which part of dimensions of managerial competence should be advanced, which will lead to gender equity and simply ensure equal opportunities for development for both genders. In this study, we do not differentiate the terms of sex and gender, which refers to being biologically woman or man and culturally associated with femininity or masculinity.

\subsection{Overview of the context of care in Indonesia}

Indonesia, officially the Republic of Indonesia, is the world's largest island country with 17,508 islands geographically located in Southeast Asia, between the Pacific and Indian oceans..$^{13}$ Indonesia consists of five major islands, namely Sumatera, Java, Sulawesi, Kalimantan, and Irian Jaya Papua. Indonesia is also called the republic of multiculturalism, which brings the motto of "strength in diversity," with a total number of population of $260,580,739 .{ }^{13}$ Indonesia is highly diverse with 700 local languages, 300 ethnics groups, and multiple religions. ${ }^{13,14}$ All Indonesians are united by one language, Bahasa Indonesia, and Pancasila as the national philosophy that is based on belief in God, humanism, unity, democracy, and justice. ${ }^{15}$

The health-care system in Indonesia is composed of primary, secondary, and tertiary level of care. The community health-care centers, called Puskesmas, and the village health posts, called Pustu, are responsible for providing the primary level of care, whereas the public and private hospitals provide the secondary and tertiary levels of care. ${ }^{13}$ Public hospitals and Puskesmas are considered the sources of revenue for government agents for carrying out community health programs $\mathrm{s}^{16,17}$ unlike private hospitals, profit-based medical institutions, which are less likely considered agents aimed at implementing public health programs. Public hospitals are owned and managed by the central government consisting of the ministry of health, police, military, and other ministry and the state-owned general agency and the local government consisting of the city government, provincial government, and district government. ${ }^{18,19}$

The first-line nurse manager in Indonesia is also called Kepala Ruangan. The required educational background for the first-line nurse manager is minimum Diploma III and Diploma IV with clinical experience of 5 years, or bachelor's level with clinical experience of 3 years. ${ }^{20}$ The Diploma III is a 3-year nursing program at the college/university level, called Ahli Madya Keperawatan, not requiring a research experience. The Diploma IV is 1-year clinical program taken after completing Diploma III program. The Bachelor/Ners is a 4-year program divided into nursing courses and basic research, followed by a 1-year internship program in a clinical or managerial or community nursing field. ${ }^{21,22}$

The term of first-line nurse managers is interchangeably used as ward managers, head nurses, unit managers, ward leaders, ward sisters, and charge nurses..$^{23,24}$ In Indonesia, neither a ward sister nor a charge nurse is considered a first-line nurse manager. ${ }^{25}$ To improve competence of first-line nurse managers, public hospitals 
have been providing various management trainings, such as ward management, professional nursing practice model called model praktek keperawatan professional - MPKP or SP $2 K P$, and emergency training, etc. In addition, career ladder for nurse managers has also been developed, which consists of 5 levels (nurse manager 1-5) and three categories (low, middle, and top managers). ${ }^{26}$ And to appreciate the works of nurse managers, a compensation scheme is provided, which is most likely in the form of remuneration as incentive (in terms of money). ${ }^{27}$ The remuneration is given based on performance, educational level, competence, length of work, achievement, services, certification, functional position, and staff classification, which all combined into index score. One index equals to 75.000 IDR (6 USD). ${ }^{28}$ These efforts are expected to motivate and improve managerial competence of first-line nurse managers among public hospitals in Indonesia.

\section{Methods}

\subsection{Study design}

This was a descriptive comparative study with a crosssectional survey to compare managerial competence between male and female first-line nurse managers among public hospitals in Indonesia.

\subsection{Sample and setting}

A total of 31,920 nurse managers were identified as the population for this study during data collection. ${ }^{29}$ A multistage approach was used to select the sample among five big islands in Indonesia, which could be described in the following three steps: (1) we identified the number of public hospitals, which consists of 795 in Java, 336 in Sulawesi, 321 in Sumatra, 112 in Kalimantan, and 32 in Papua ${ }^{29}$; (2) we divided each type of public hospital in each island with equivalent ratio 60:1 As a result, 25 public hospitals were included, with 11 in Java, 6 in Sumatra, 3 in Sulawesi, 3 in Kalimantan, and 2 in Papua; (3) we selected all participants by total sampling, which consists of 369 first-line nurse managers. However, of those, only 259 participants from 18 hospitals were able to respond ( $70.1 \%$ response rate). Of the 259 participants, 3 were removed as they were detected as outliers during testing for normal data distribution. Therefore, the final sample had 256 participants for this study.

The inclusion criteria of the sample were head nurses, nursing unit managers, or ward head nurses who worked in a public hospital for at least 1 year, including in outpatient unit, inpatient unit, emergency unit, intensive care unit, and operating room. The exclusion criteria were charge nurses and ward sisters.

\subsection{Measures}

Managerial competence is a first-line nurse manager's behavior in carrying out specific managerial tasks, functions, or job responsibilities that reflect his/ her knowledge, skills, and attitudes. ${ }^{30}$ For the purpose of this study, managerial competence is operationally defined as the behavior of head nurses, nursing unit managers, ward manager, or ward leaders that reflects their knowledge, skill, and attitude in applying quality care improvement, utilizing informatics, facilitating spiritual nursing care, performing leadership, managing self, staffing and professional development, and managing finance in public hospitals in Indonesia, which is measured by the Indonesian First Line Nurse Managers Managerial Competence Scale (I-FLNMMCS). ${ }^{31}$ The scale consists of 43 items in 7 dimensions. The scale was developed in Indonesian language with high validity and reliability, with overall Cronbach's $\alpha$ of the scale was 0.95 , and ranged from 0.71 to 0.90 for the dimensions. The scale consists of 5 ratings, namely, 5 Always, 4 Quite often, 3 Sometimes, 2 Once in a while, and 1 None of the time. A higher mean score represents a higher competence.

\subsection{Data collection}

Data were collected from January to May 2018 by the first author assisted by local research project coordinators (nurses who have research experience). Prior to data collection, the authors ensured that all coordinators were given the explanation about the objective and procedure of the research. The job descriptions of local research project coordinators were: (1) to ensure that the permission has been granted for the study to collect data, (2) to meet participants to sign an informed consent if they agree to participate and ask them to fill questionnaire, and (3) to check the completeness of the questionnaires.

\subsection{Data analysis}

Data were analyzed using descriptive analyses using mean and standard deviation to describe managerial competence of first-line nurse managers. As data were normally distributed, Independent $t$-test was used to compare two sample means from male and female groups. SPSS version 22 was used for data analyses. 


\subsection{Ethical consideration}

The Institutional Review Board (IRB) approval was obtained from the research ethics committee of the university. Prior to data collection, each participant signed an informed consent and was explained about the study's objectives and procedures. In this study, the names of public hospitals were not mentioned for confidentiality.

\section{Results}

Findings showed that both male and female first-line nurse managers had no difference in managerial competence $(P=0.555)$, as well as in its each dimensionapplying quality care improvement $(P=0.251)$, utilizing informatics $(P=0.142)$, facilitating spiritual nursing care $(P=0.219)$, leadership $(P=0.869)$, self-management $(P=0.486)$, staffing and professional development $(P=0.693)$, and financial management $(P=0.602)$ (see Table 1). Seen from the mean score, female nurse managers reported higher in facilitating spiritual nursing care (mean $=3.77, \mathrm{SD}=0.744$ ), managing self (mean $=3.69, \mathrm{SD}=0.764)$, staffing and professional development $($ mean $=3.59, \mathrm{SD}=0.991)$, utilizing informatics (mean $=3.85$, SD $=0.766$ ), and applying quality care improvement (mean $=3.91, \mathrm{SD}=0.7801$ ). Male nurse managers reported higher in leadership (mean $=369, \mathrm{SD}=0.651$ ) and financial management (mean $=3.22, \mathrm{SD}=0.857$ ).

Descriptively, the highest dimension of managerial competence according to the gender was applying quality care improvement, with an average of 3.91 for female nurse managers and 3.77 for male nurse managers. The lowest dimension was in financial management, with an average of 3.15 for female managers and 3.22 for male managers.

Table 2 shows that female nurse managers rated a little higher than male nurse managers in all activities of the quality care improvement dimension. It could be probably said that female nurse managers were good at quality improvement. In utilizing informatics dimension,

\begin{tabular}{|c|c|c|c|c|}
\hline \multirow[t]{2}{*}{ Managerial competence } & Male $(n=54)$ & Female $(n=202)$ & \multirow[t]{2}{*}{$t$} & \multirow[t]{2}{*}{$p$} \\
\hline & Mean \pm SD & Mean \pm SD & & \\
\hline Applying quality care improvement & $3.77 \pm 0.902$ & $3.91 \pm 0.801$ & -1.151 & 0.251 \\
\hline Utilizing informatics & $3.68 \pm 0.725$ & $3.85 \pm 0.766$ & -1.475 & 0.142 \\
\hline Facilitating spiritual nursing care & $3.62 \pm 0.763$ & $3.77 \pm 0.744$ & -1.232 & 0.219 \\
\hline Leadership & $3.69 \pm 0.651$ & $3.67 \pm 0.703$ & 0.165 & 0.869 \\
\hline Self-management & $3.61 \pm 0.761$ & $3.69 \pm 0.764$ & -0.697 & 0.486 \\
\hline Staffing and professional development & $3.53 \pm 1.130$ & $3.59 \pm 0.991$ & -0.395 & 0.693 \\
\hline Financial management & $3.22 \pm 0.857$ & $3.15 \pm 0.840$ & 0.522 & 0.602 \\
\hline Total dimension & $3.62 \pm 0.632$ & $3.67 \pm 0.635$ & -0.592 & 0.555 \\
\hline
\end{tabular}

Note: Independent $t$-test results with a significant value of $<0.05$.

Table 1. Managerial competence according to gender $(N=256)$.

\begin{tabular}{|c|c|c|c|c|}
\hline \multirow[t]{2}{*}{ Items } & \multicolumn{2}{|c|}{ Male } & \multicolumn{2}{|c|}{ Female } \\
\hline & Mean & SD & Mean & SD \\
\hline \multicolumn{5}{|l|}{ Applying quality care improvement } \\
\hline Continually understanding and measuring quality of care in terms of structure, process, and outcomes & 3.72 & 1.12 & 3.84 & 1.06 \\
\hline Using evidence-based practice in nursing care & 4.15 & 0.96 & 4.31 & 0.90 \\
\hline Analyzing the workflow of unit and identifying errors, causes, and their effects in nursing service & 3.56 & 1.09 & 3.82 & 0.95 \\
\hline Actively participating in setting nursing practice standards or guidelines for nursing care in unit & 3.67 & 1.13 & 3.70 & 1.14 \\
\hline \multicolumn{5}{|l|}{ Utilizing informatics } \\
\hline Utilizing technology to manage patients & 3.33 & 0.99 & 3.33 & 1.05 \\
\hline Integrating technology into nursing documentation & 3.48 & 1.37 & 3.57 & 1.25 \\
\hline Evaluating the effect of information technology (IT) on patient care and delivery system & 4.13 & 0.87 & 4.51 & 0.73 \\
\hline Using information system to support nursing practice & 3.80 & 0.98 & 4.01 & 1.01 \\
\hline
\end{tabular}

Table 2. Applying quality care improvement and informatics utilization dimension of managerial competence according to gender $(N=256)$. 
female first-line nurse managers rated higher than male first-line nurse managers in a way of evaluating information technology (IT) impact on patient care, using IT for supporting nursing practice, and integrating IT in nursing documentation. Both genders rated equally in using technology to manage patients.

In the dimension of facilitating spiritual nursing care, Table 3 shows that male nurse managers rated lower than female nurse managers in almost all activities, except in coaching or mentoring problem-solving skills, in which male nurse managers rated higher than female nurse managers.

Table 4 shows that there was likely a difference between both managers in shared decision-making, being role model, and providing positive feedback, which female managers rated higher than male managers. In the evaluation of staff performance, male nurse managers rated higher than female nurse managers, whereas the other activities were seen to be similar. However, both managers were rated very low in facilitating nurse staff in collaboration with medical doctors.

In self-management activities, Table 5 shows that female nurse managers rated higher than male nurse managers in almost all activities, except in the attendance of regular supervision or consultation with superordinates. In staffing and professional development, it was likely that female nurse managers rated higher in the evaluation of staff needs, opportunities and trainings providers for staff, and competence-based matching with patient acuity. However, they rated lower in managing the number and qualification of staff. In addition, financial management activities were likely to be equal in both managers, except in coordinating with supervisors,

\begin{tabular}{|c|c|c|c|c|}
\hline \multirow[t]{2}{*}{ Activities } & \multicolumn{2}{|c|}{ Male } & \multicolumn{2}{|c|}{ Female } \\
\hline & Mean & SD & Mean & SD \\
\hline Relieving staff spiritual distress & 3.63 & 1.10 & 3.87 & 0.92 \\
\hline Reviewing and identifying the influence of cultural beliefs, values, and spiritual on nursing care & 3.37 & 1.31 & 3.56 & 1.21 \\
\hline Explaining and demonstrating spiritual care practice to staff and patients & 3.44 & 1.18 & 3.63 & 1.11 \\
\hline $\begin{array}{l}\text { Referring effectively and articulately to other spiritual nursing care based on the situation and preference of staff } \\
\text { and patient }\end{array}$ & 3.35 & 1.20 & 3.47 & 1.19 \\
\hline Paying attention to the spiritual needs of staff & 3.31 & 1.13 & 3.45 & 1.23 \\
\hline Facilitate staff to provide spiritual nursing care to patient and families and respect their diversity and differences & 4.06 & 0.96 & 4.22 & 0.85 \\
\hline Coaching or mentoring staff in developing problem-solving skills & 4.24 & 0.82 & 4.20 & 0.83 \\
\hline
\end{tabular}

Table 3. Facilitating spiritual nursing care dimension of managerial competence according to gender $(N=256)$

\begin{tabular}{|c|c|c|c|c|}
\hline \multirow[t]{2}{*}{ Activities } & \multicolumn{2}{|c|}{ Male } & \multicolumn{2}{|c|}{ Female } \\
\hline & Mean & SD & Mean & SD \\
\hline $\begin{array}{l}\text { Facilitating nursing staff in collaboration with other health professions in practice, especially with medical } \\
\text { doctors in providing patient-centered care }\end{array}$ & 2.41 & 1.41 & 2.13 & 1.38 \\
\hline Shared decision-making by involving staff in the process of change & 2.19 & 1.39 & 4.20 & 0.83 \\
\hline Effectively assigning task responsibility and authority to subordinates & 4.05 & 0.99 & 4.09 & 0.96 \\
\hline Establishing mutual trust and respect by dealing with others in a fair manner & 4.13 & 0.91 & 4.01 & 0.94 \\
\hline Arranging schedules and supporting flexible self-scheduling for staff & 4.04 & 0.93 & 4.04 & 1.08 \\
\hline Advocating for staff in assertive and confident manner & 4.21 & 0.95 & 4.17 & 0.98 \\
\hline Giving safe and proper legal and ethical care & 3.52 & 1.19 & 3.46 & 1.45 \\
\hline Becoming role model of professional and visioning behavior & 3.47 & 1.39 & 3.96 & 0.80 \\
\hline Leading and inviting staff to pray before working in the unit & 4.11 & 0.93 & 4.08 & 0.91 \\
\hline Collaborating and communicating with other health professions in inter-disciplinary team & 3.37 & 1.07 & 3.20 & 1.46 \\
\hline Providing positive feedback and reinforcement for improvement of staff performance & 3.24 & 1.38 & 3.80 & 1.09 \\
\hline Identifying strengths of staff and capitalizing on those strengths & 4.08 & 1.00 & 4.02 & 1.02 \\
\hline Dealing with anger, criticism, and frustration in a constructive manner & 3.39 & 1.12 & 3.44 & 1.19 \\
\hline Evaluating nurses staff performance based on standard and key performance indicators & 3.43 & 1.17 & 2.56 & 1.51 \\
\hline
\end{tabular}

Table 4. Leadership dimension of managerial competence according to gender $(N=256)$. 


\begin{tabular}{|c|c|c|c|c|}
\hline \multirow[t]{2}{*}{ Items } & \multicolumn{2}{|c|}{ Male } & \multicolumn{2}{|c|}{ Female } \\
\hline & Mean & SD & Mean & $\mathrm{SD}$ \\
\hline \multicolumn{5}{|l|}{ Self-management } \\
\hline Getting involved in professional associations and professional development programs & 3.61 & 1.22 & 3.92 & 1.01 \\
\hline Engaging in self-evaluation program in the hospital & 3.70 & 1.18 & 3.81 & 1.13 \\
\hline Involved in developing a policy brief and advocacy to policy makers & 4.30 & 0.72 & 4.5 & 0.74 \\
\hline Achieving certification in an appropriate field/specialty & 3.59 & 1.16 & 3.57 & 1.26 \\
\hline $\begin{array}{l}\text { Managing self through continuing education and participating in nursing management research/training/ } \\
\text { course }\end{array}$ & 3.76 & 1.04 & 3.84 & 1.04 \\
\hline Engaging in regular supervision or consulting with superordinates & 2.74 & 1.39 & 2.55 & 1.39 \\
\hline \multicolumn{5}{|l|}{ Staffing and professional development } \\
\hline Managing the number and qualification of nurse staff based on the standard of hospital & 3.56 & 1.44 & 3.47 & 1.45 \\
\hline Determining and evaluating staffing needs & 3.54 & 1.25 & 3.62 & 1.15 \\
\hline $\begin{array}{l}\text { Setting up learning opportunities, trainings, and continuing education and others related to nurse staff } \\
\text { development }\end{array}$ & 3.50 & 1.34 & 3.70 & 1.26 \\
\hline Identifying and matching the competence of nurse staff with patient acuity & 3.56 & 1.28 & 3.60 & 1.26 \\
\hline \multicolumn{5}{|l|}{ Financial management } \\
\hline $\begin{array}{l}\text { Actively participating in arranging a practical annual budget for the unit that includes volume, revenue, } \\
\text { personnel, supplies, and capital equipment }\end{array}$ & 3.59 & 1.22 & 3.53 & 1.35 \\
\hline Communicating fiscal management expectations and outcomes to staffs and other stakeholders & 2.43 & 1.47 & 2.46 & 1.43 \\
\hline Implementing cost-benefit analysis approach in financial plan in the unit & 4.24 & 0.70 & 4.33 & 0.72 \\
\hline Coordinating with supervisors among departments & 2.63 & 1.40 & 2.30 & 1.44 \\
\hline
\end{tabular}

Table 5. Dimensions of self-management, staffing and professional development, and financial management according to gender $(N=256)$.

in which female nurse managers rated a little lower than male nurse managers.

\section{Discussion}

Findings of this study showed that managerial competence between male and female first-line nurse managers was not significantly different. These findings were not in line with the results of previous studies, which indicated that female and male managers are different in terms of the way they perform their managerial jobs. ${ }^{3,4}$ However, the average scores in each dimension of managerial competence vary between male and female managers, which was similar with the literature said that there was only a slight difference in competence between female and male managers. ${ }^{2}$

In the application of quality care improvement dimension, female nurse managers rated higher in all care quality activities, which might be influenced by the characteristics of females who are very good at caring. ${ }^{6}$ However, both managers were good at using evidencebased practice, but female nurse managers rated higher than male managers. This result was in line with previous study that revealed that females were more likely to use evidence-based practice and adhere clinical guidelines than males. ${ }^{32}$ However, in a total score of quality care improvement dimension, both managers had no significant difference, which was in contrast with a previous study, which revealed that there were differences in behavior, attitude, and clinical decision-making between male and female health providers toward quality care improvement. ${ }^{33}$

In the dimension of utilizing informatics, female nurse managers had a slightly higher score than that of male nurse managers. The female managers rated higher in the integration of technology in nursing documentation and evaluation of IT on patient care and delivery system as well as its utilization in supporting nursing practices. However, both nurse managers rated similarly in utilizing technology in managing patients. These findings were in contrast with the theory that emphasizes that technology has a masculine image.$^{34,35}$ Therefore, theories that associate computers with masculinity are not universally applicable. ${ }^{36}$ Our findings also proved that male and female nurse managers were more likely to be equal in managerial competence related to the informatics.

In the dimension of facilitating spiritual nursing care, our findings showed that female nurse managers rated a little higher than male nurse managers, which was in line with the social role theory that indicated that women are likely to be communal (e.g., sensitive, understanding) than men, ${ }^{6}$ and it would be easy for females to advance 
in this competence in accordance to their characteristics. However, it does not indicate that female nurse managers were more spiritual than male managers.

As viewed from the average score, female nurse managers were most likely to rate higher than male nurse managers in all activities. This was stereotypically in line with the feminism perspective that is associated with understanding and caring. ${ }^{37}$ Understanding individual's spiritual needs and preferences is not an easy task, which is influenced by cultural belief and values with all diversities and differences. ${ }^{38}$ Additionally, male nurse managers rated higher only in coaching staff in advancing problem-solving skills, which might reflect that male nurse managers need more training in facilitating spiritual nursing care. However, as spiritual influences health and well-being, ${ }^{39}$ facilitating spiritual nursing care is very important component not only for nurse staff but also for patients.

In the leadership dimension, male nurse managers rated a little higher than female nurse managers. Seen from each activity of leadership, both male and female nurse managers rated lower in facilitating intercollaboration between nurse staff and medical doctors although male nurse managers had a slightly higher score than female nurse managers. This reflects that there is a gap between nurses and medical doctors that needs to be addressed. The first-line nurse managers should be able to facilitate their staff.

In addition, male nurse managers rated higher in a way of establishing mutual trust and respect, advocating staff, giving proper legal care, leading, collaborating and communicating with other professions, identifying strengths of staff, and evaluating performance. But, they rated very low in shared decision-making, which might stereotypically reflect the characteristics of males with command and control behavior, competitive, aggressive, dominant, and ambitious. ${ }^{6}$ Otherwise, female nurse managers rated higher in shared decisionmaking, delegation, being role model, providing positive feedback, and dealing with conflict constructively, which support the evidence from previous studies that female managers are typically caring, supporting, and transformative..$^{5,6}$ However, both managers were good at supporting flexible schedule for their staff. Thus, it could be said that although the average scores reflect some differences in several leadership activities, both male and female nurse managers may behave similarly in the way they perform the leadership and managerial behavior, which is against the earlier belief that there was a significant gender difference in leadership and management. ${ }^{40}$

In the dimension of self-management, male nurse managers rated lower than female nurse managers.
Male nurse managers rated a little higher in getting a specialty certification and joining regular supervision and consultation with superordinates, which indicted that there were personal efforts of male managers in managing and developing themselves. Female managers rated a little higher in engaging in self-evaluation and professional development program, involving in developing policy brief, and participating in research and training. These findings were similar to those of a previous study that stated that female managers are better in putting constant effort for self-management than male managers. ${ }^{41}$ Our study results provide the insight of differences in a way male and female managers managed themselves to be competent managers. However, it is hard to imagine a productive manager without self-management skills and efforts. ${ }^{42}$

In the dimension of staffing and professional development, female nurse managers rated a little higher than male nurse managers. It is noteworthy to emphasize that female nurse managers rated higher in determining and evaluating staffing needs, setting and providing learning opportunities for staff, and matching staff competence with patient acuity, whereas male nurse managers rated higher in managing the number and qualification of staff based on the hospital standard. This finding is against a previous study that indicated staffing, professional development, and human resources are only good for females. ${ }^{6}$ However, male managers also had good skills in staff management because caring is the core of nursing, ${ }^{43}$ regardless of the gender.

In financial management dimension, both nurse managers rated very low in the communication of fiscal management's outcomes and coordinating with supervisors although female nurse managers rated little higher than male nurse managers. This reflects that there is a gap between first-line nurse managers and supervisors in financial management. Female nurse managers were less likely to actively participate in arranging a practical annual budget for the unit than male nurse managers, but were more likely to implement cost-benefit analysis. However, in the total score of this dimension, female nurse managers had lower score than male nurse managers', which was in contrast with the findings of a previous study that revealed females are more likely to report using sound financial practices than males. ${ }^{44}$ In addition, our findings showed no significant difference in financial management between both managers, which is against the finding of a previous study that stated males and females had different financial behavior. ${ }^{45,46}$

In conclusion, seen from the total score of managerial competence, male and female nurse managers were statistically similar in their managerial competence, which reflect the equity between them although gender 
stereotypes are still attached to nursing as a female job in Indonesia. Does it happen because men adopt women characteristics in their managerial and leadership competence? Do men feel less dominant when working in women-dominated profession? As literature said, men will show less authority if they work in similar managerial jobs, which are associated with women. ${ }^{12}$ However, this assumption can be better explained in the future research.

\subsection{Implication for nursing management practice}

Our findings provide the benefits of having a different group (male group) within nursing, which bring the equity in nursing leadership and management. Because female is often viewed as caring and nurturing, and male is seen as assertive and has a sense of dominance; however, our findings are against that stereotype, which say caring and leadership competence in both male and female nurse managers are remarkably similar. Managerial competence is not rooted in fixed gender traits, but seen from the response of the first-line nurse managers in particular circumstances, which depends on the context of the setting, organizational structures, hospital practices, and pattern of interaction that creates different experiences for them.

This result also fits with the paradigm of genderblind view, which indicates that male and female leaders are equally treated because male managers are as competent as female managers. ${ }^{7}$ Therefore, bias, discrimination, and stereotyping among male and female managers should be eliminated. In addition, findings of this study also highlight the importance of addressing gender equity in human resource management activities, including in the process of recruitment and selection, training and development, rewards, performance appraisal, and career planning. Gender-related barriers will lock the potential of the performance of first-line nurse managers. This study also suggests the top managers not to fix male or female managers in increasing their managerial competence, but to fix the situations that reinforce gender stereotypes.

\subsection{Limitation of the study}

A gender difference in this study does not reflect actual managerial competence among first-line nurse managers, but the insight of gender difference in self-ratings of their competence. In addition, unequal sample size between the two groups and the use of cross-sectional design might limit the generalization of the findings, and the use of self-reported assessment might result in response bias.

\section{Conclusions}

The managerial competence of male and female firstline nurse managers among public hospitals in Indonesia was not statistically different although nursing is still stereotypically attached to female profession. Gender stereotypes in nursing did not affect first-line nurse managers in performing their managerial roles and responsibilities. Therefore, leadership and managerial trainings and professional developments among them should be treated equally and not in accordance with the gender. Based on the findings of this study, it would be of interest to qualitatively assess the lived experiences of male first-line nurse managers working in the female-dominated environment, understand how they feel, and what they need to understand the issue comprehensively. It is also suggested that nursing organizations need to improve the skills and performance of both managers and reduce the gender bias and stereotype in nursing. In addition, nursing educational institutions are recommended to actively recruit more men into nursing science.

\section{Acknowledgments}

This study was supported by Second Century Fund $(\mathrm{C} 2 \mathrm{~F})$ and the Faculty of Nursing, Chulalongkorn University, Bangkok, Thailand. Funding for data collection was supported by the 90th Anniversary of Chulalongkorn University Scholarship (Ratchadaphiseksomphot Endowment Fund). The authors acknowledge the PhD committees, the Indonesian first-line nurse managers who have participated in this study, and the research assistants for valuable contributions.

\section{Ethical consideration}

This study is a part of PhD Dissertation Project titled "Factors Influencing Managerial Competence of FirstLine Nurse Managers at Public Hospitals in Indonesia." This study was ethically approved by the Medical and Health Research Ethics Committee (MHREC) of the Faculty of Medicine Gadjah Mada University on May 17, 2017, with No. KE/FK/0565/EC/2017. Written informed consent was obtained from all the participants. Although we got permission from each hospital, not all hospitals tend to agree to put the names of hospitals into publication. Therefore, we do not publish hospitals' names in this article.

\section{Conflicts of interest}

All contributing authors declare no conflicts of interest. 
1. Trossman S. Complex role in complex times. Programs take aim at helping nurse managers lead nurses. Am Nurse. 2011;43:1-6.

2. Chase. Nurse Manager Competencies. Iowa: University of lowa; 2010.

3. Costa PT Jr, Terracciano A, McCrae RR. Gender differences in personality traits across cultures: robust and surprising findings. J Pers Soc Psychol. 2001;81:322-331.

4. Kark R, Eagly AH. Gender and leadership: negotiating the labyrinth. In: Chrisler JC, McCreary DR, eds. Handbook of Gender Research in Psychology. New York: Springer; 2010.

5. Eagly AH, Johnson BT. Gender and leadership style: a meta-analysis. Psychol. Bull. 1990;108:233.

6. Eagly $\mathrm{AH}$, Karau SJ. Role congruity theory of prejudice toward female leaders. Psychol Rev. 2002;109:573.

7. Jonsen K, Maznevski ML, Schneider SC. Gender differences in leadership-believing is seeing: implications for managing diversity. Equal Div Incl. 2010;29:549-572.

8. Fielden S, Burke RJ. Gendered careers in nursing. Gender Manage. 2014;29. doi:10.1108/ GM-07-2013-0074.

9. Infodatin. Situation of nursing workforce in Indonesia. Jakarta: Pusat Data dan Informasi Kementerian Kesehatan Indonesia; 2017.

10. Gunawan J. Nursing and men: a gender bias. Belitung Nurs J. 2017;3:52-53.

11. Stanley D, Beament T, Falconer D, et al. The male of the species: a profile of men in nursing. $J A d v$ Nurs. 2016;72:1155-1168.

12. Thebaud S, Doering L. How a job acquires a gender (and less authority if it's female); 2017. http://theconversation.com/how-a-job-acquiresa-gender-and-less-authority-if-its-female-79164. Accessed January 18, 2019.

13. Central Intelligence Agency. The world factbook of Indonesia population; 2018. Web site. https:// www.indexmundi.com/indonesia/population.html. Accessed January 18, 2019.

14. BBC News. Indonesia country profile; 2018. https:// www.bbc.com/news/world-asia-pacific-14921238. Accessed January 18, 2019.

15. Gunawan J, Aungsuroch Y. Indonesia health care system and ASEAN economic community. Int $J$ Res Med Sci. 2015;3:1571-1577.
16. National Research Council. Reducing Maternal and Neonatal Mortality in Indonesia: Saving Lives, Saving the Future. Washington, DC: National Academies Press; 2013.

17. Hull TH. Reducing maternal and neonatal mortality in Indonesia: saving lives, saving the future. Bull Indones Econ Stud. 2015;51:154-155.

18. President of Indonesia. Hospital Act No 44 Year 2009. Jakarta: President of the Republic of Indonesia; 2009.

19. Ministry of Health. Health Profile Data of Indonesia. Jakarta: Ministry of Health, The Republic of Indonesia; 2017.

20. Ministry of Health. Regulation of the Ministry of Health of the Republic of Indonesia no 40 year 2017 about Development of Professional Career Ladder of Clinical Nurses. Jakarta: Ministry of Health, the Republic of Indonesia; 2017.

21. Sekarsari R. Nursing services in Indonesia. Bangkok, Thailand: International Symposium: Enhancing Nursing Education and Nursing Service in ASEAN. Faculty of Nursing, Chulalongkorn University; 2-4 July 2013.

22. President of Indonesia. Nursing Act No 38 Year 2014. Jakarta, Indonesia: President of the Republic of Indonesia; 2014.

23. Finkelman AW. Leadership and Management in Nursing. United States: Pearson Prentice Hall; 2006.

24. Wynne R. Clinical nurses' response to an environment of health care reform and organizational restructuring. J Nurs Manage. 2003;11:98-106.

25. Gunawan J, Aungsuroch Y, Nazliansyah, et al. The lived experiences of becoming first-line nurse managers: a phenomenological study. Iran J Nurs Midwifery Res. 2018;23:66.

26. Indonesian Nurse Managers Association. Nursing ward management in H. Adam Malik Hospital; 2016. http://rsham.co.id/wp-content/uploads/2016/02/ Manajemen-Ruang-Rawat-_agustus_-2016.pdf. Accessed January 18, 2019.

27. Gunawan J. "This is 2019 ! But i still need to work double shifts and have multiple jobs to keep me alive": a phenomenon among nurses in Indonesia. Belitung Nurs J. 2019;5:108-110.

28. Suprajitno. Nursing remuneration index. J Ners. 2013;8:357-374.

29. Ministry of Health of Indonesia. Hospital data online. Ministry of Health of Indonesia; 2016. http://sirs. yankes.kemkes.go.id/fo/. Accessed March 17, 2016. 
30. Gunawan J, Aungsuroch Y. Managerial competence of first-line nurse managers: a concept analysis. Int J Nurs Pract. 2017;23:e12502.

31. Gunawan J, Aungsuroch $\mathrm{Y}$, Fisher ML, et al. Development and psychometric properties of managerial competence scale for first-line nurse managers in Indonesia. SAGE Open Nurs. 2019;5:2377960819831468.

32. Tsugawa Y, Jena AB, Figueroa JF, et al. Comparison of hospital mortality and readmission rates for Medicare patients treated by male vs female physicians. JAMA Intern Med. 2017;177:206-213.

33. Pittman P, Blatt G, Rodriguez P. An assessment of the impact of health workers for change in Avellaneda, province of Buenos Aires, Argentina. Health Policy Plann. 2001;16:40-46.

34. Wajcman J. Feminism Confronts Technology. University Park, PA: Pennsylvania State University Press; 1991.

35. Phipps A. Engineering women: the gendering' of professional identities. Int $J$ Eng Educ. 2002;18:409-414.

36. Gupta N. Rethinking the relationship between gender and technology: a study of the Indian example. Work Employ Soc. 2015;29:661-672.

37. Draulans V. Gender and spirituality. In: Bouckaert L, Zsolnai L, eds. Handbook of Spirituality and Business. London: Palgrave Macmillan; 2011.
38. Mayer C-H, Surtee S, Barnard A. Women leaders in higher education: a psycho-spiritual perspective. SA J Psychol. 2015;45:102-115.

39. Temane QM, Wissing MP. The role of spirituality as a mediator for psychological well-being across different contexts. SA J Psychol. 2006;36: 582-597.

40. Burke S, Collins KM. Gender differences in leadership styles and management skills. Women Manag Rev. 2001;16:244-257.

41. Eagly AH, Carli LL. The female leadership advantage: an evaluation of the evidence. Leadersh Q. 2003;14:807-834.

42. Linman D. Self-management skills for employees, or how to be a productive employee; 2011. https:// mymanagementguide.com/self-managementskills-for-employees-or-how-to-be-a-productiveemployee/. Accessed January 17, 2019.

43. Jeffery $A D$. The art of nursing leadership. Nurs Lead. 2013;11:48-51.

44. Hayhoe CR, Leach LJ, Turner PR, et al. Differences in spending habits and credit use of college students. J Consum Aff. 2000;34:113-133.

45. Fisher P. Gender differences in personal saving behaviors. J Financ Couns Plan. 2010;21:14-24.

46. Theodos B, Kalish E, McKernan S-M, et al. Do financial knowledge, behavior, and well-being differ by gender? Urban Inst. 2014. 